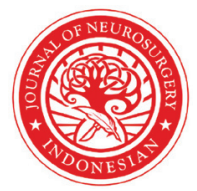

Indonesian Journal of Neurosurgery

\section{Profile of the brain arteriovenous malformation at National Brain Center hospital in 2015 - 2016: Epidemiological study}

\author{
Ditto Darlan ${ }^{1 *}$, Abrar Arham², Muhammad Arief Rachman Kemal ${ }^{3}$
}

${ }^{1}$ Neurosurgery Resident, Faculty of Medicine, Universitas Airlangga, Surabaya, Indonesia;

${ }^{2}$ Neurosurgery Consultant, National Brain Center Hospital, Jakarta, Indonesia;

${ }^{3}$ Neurology Consultant, National Brain Center Hospital, Jakarta, Indonesia;

*Corresponding author:

Ditto Darlan;

Neurosurgery Resident, Faculty of

Medicine, Universitas Airlangga,

Surabaya, Indonesia;

dittodarlan@hotmail.com

Received: 2021-07-02

Accepted: 2021-10-28

Published: 2021-12-05

\section{ABSTRACT}

Introduction: Brain arteriovenous malformation (AVM) is a congenital vascular lesion in which arterial blood flows directly into draining veins without capillary networking. The estimated incidence rate is approximately 1 case for 100,000 people a year. Clinical presentations are headache, seizure, neurological deficit, and others that are caused by space-occupying lesions. The treatment of brain AVM consists of microsurgery resection, embolization, stereotactic radiosurgery to conservative treatment.

Methods: The design of the study was a descriptive non-analytical study. Data were taken from patients' medical records, radiological records, and catheter lab data records at National Brain Center Hospital in 2015 - 2016.

Results: There were 32 patients with AVM. The characteristics of brain AVM in our study were mostly men (62.5\%), productive age ranging from 20 - 29 years (31.25\%), manifested as seizure (43.75\%), presence with Glasgow Coma Scale (GCS) score 15 (87.5\%), and rupture of brain AVM nidus (59.38\%).

Conclusion: Brain AVM predominantly occurred at a young age and the management varied on the Spetzler-Martin grading. In addition, the likelihood of rupture was influenced by the characteristics of the lesion, such as size, age, location of the nidus, and history of rupture of brain AVM nidus.

Keywords: brain arteriovenous malformation, epidemiology, profile.

Cite This Article: Darlan, D., Arham, A., Kemal, M.A.R. 2021. Profile of the brain arteriovenous malformation at National Brain Center hospital in 2015 - 2016: Epidemiological study. Indonesian Journal of Neurosurgery 4(3): 116-119. D0I: 10.15562/ijn. v4i3.186

\section{INTRODUCTION}

Brain arteriovenous malformation (AVM) is a congenital vascular lesion in which arterial blood flows directly into draining veins without capillary networking. ${ }^{1}$ The reduction in vascular resistance is generally due to the small diameter of the arterioles and capillaries, which causes direct flow from the arterial pressure to the venous structures resulting in increased blood flow accompanied by tortuous growth of the blood vessels. ${ }^{1}$ Apart from anatomical changes in the cerebral blood vessels, these processes cause significant hemodynamic changes in the brain. For example, they include reversed venous flow, venous hypertension, and hypoperfusion in the region around the lesion. ${ }^{1}$ Brain AVM is possibly a congenital disorder that occurs in the embryonic phase of fetal development. ${ }^{1}$ However, it is not an inherited lesion. Until now, the etiology is still uncertain. Although brain AVM has heterogeneity in vascular size and architecture, cases of multiple brain AVM in one patient are sporadic. The incidence rate is 1 case in 100,000 population per year even though the incidence rate continues to increase with the modern radiological support devices. ${ }^{1}$ The most common clinical symptom is a hemorrhagic stroke caused by ruptured brain AVM nidus. In addition, brain AVM has symptomatic mass effects, seizures, and pathological changes in hemodynamics caused by irritation of the cortex around the lesion. ${ }^{1,2}$

Spetzler-Martin divides the brain AVM into three classifications based on the nidus, eloquent area, and draining vein size. ${ }^{3}$ Eloquent is the location of the nidus in areas that have specific functions such as the sensory-motor area, the speech area, the visual area, the basal ganglia, the ventricular system, the brainstem, and the cerebellum. ${ }^{3}$ Meanwhile, draining veins are divided into two, which are superficial and deep. The classification is related to the management that will be given. Direction is adjusted to the brain AVM nidus condition, whether the brain AVM nidus condition is ruptured or intact. In the state where there is a ruptured nidus, hemodynamic stabilization is performed first; then definitive action is taken. ${ }^{4}$ Definitive measures are in the form of microsurgery, embolization, and radiosurgery. ${ }^{5,6}$ In Spetzler-Martin grading, grade I - II are managed with one treatment modality, grade III is managed with multimodality, and grade IV - V are managed conservatively. $3,5,6$

Currently, the management of brain AVM patients with intact nidus is still a matter of debate. Therefore, this epidemiological study is hoped to assist in the service guidelines for brain AVM 
patients.

\section{METHODS}

This study was an epidemiological study using secondary data from medical records and radiology patients at the National Brain Center Hospital. The research design was descriptive non-analytic. The population in this study was all brain AVM patients at the National Brain Center Hospital who were handled and had complete medical records. Both identity, chief complaints, GCS, radiological data, and management were given in 2015 - 2016 .

\section{RESULTS}

The total number of brain AVM patients was 32 people. Thirteen patients were treated in 2015, and nineteen patients were treated in 2016. Based on Table 1, 62.5\% of the patients were male, the highest percentage in gender.

Based on Fig. 1A, The highest percentage of brain AVM by age was in productive $(31.25 \%)$, ranging from 20 29 years. It was found that all brain AVM

Table 1. Prevalence of brain arteriovenous malformation with variable clusterization.

\begin{tabular}{lcccc}
\hline \multicolumn{1}{c}{ Variable } & $\mathbf{2 0 1 5}$ & $\mathbf{2 0 1 6}$ & Total & $\%$ \\
\hline Gender & 6 & 14 & 20 & 62.5 \\
Male & 7 & 5 & 12 & 37.5 \\
Female & & & & \\
GCS & 0 & 0 & 0 & 0 \\
$3-8$ & 0 & 0 & 0 & 0 \\
$9-13$ & 0 & 4 & 4 & 12.5 \\
14 & 13 & 15 & 28 & 87.5 \\
15 & & & & \\
Chief complaints & 2 & 8 & 10 & 31.25 \\
Headache & 6 & 8 & 14 & 43.75 \\
Seizure & 0 & 2 & 2 & 6.25 \\
Decrease of consciousness & 4 & 1 & 5 & 15.63 \\
Hemiparesis & 1 & 0 & 1 & 3.13 \\
Cranial nerve lesion & & & & \\
Nidus condition & 7 & 6 & 13 & 40.62 \\
Intact & 6 & 13 & 19 & 59.38 \\
Rupture & & & & \\
Management & 4 & 3 & 7 & 23.33 \\
Conservative & 3 & 10 & 13 & 43.34 \\
Embolization & 0 & 4 & 4 & 13.33 \\
Microsurgery & 4 & 0 & 4 & 13.33 \\
Radiosurgery & 1 & 0 & 1 & 3.33 \\
Multimodality & & & & \\
Unfinished & & & & \\
\hline Combination of & & & & \\
\hline
\end{tabular}

* Combination of embolization and microsurgery

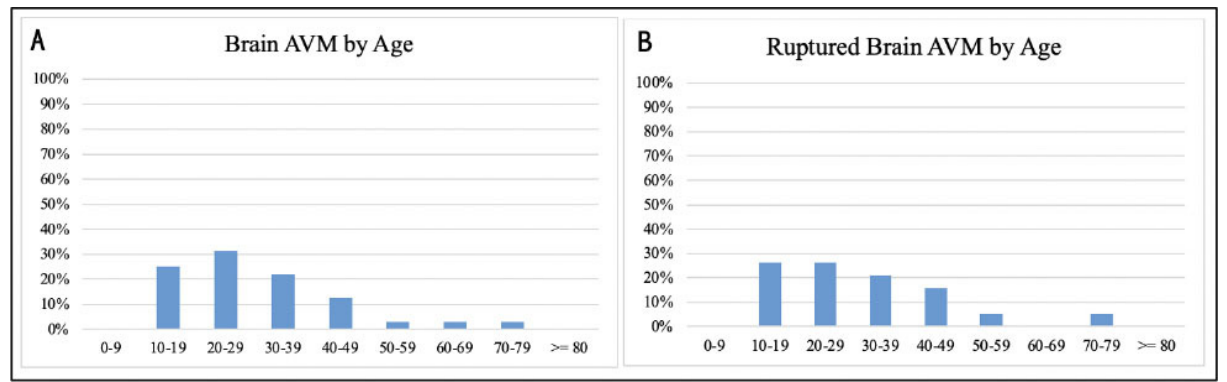

Figure 1. A. Prevalence of brain arteriovenous malformation with age clusterization; B. Prevalence of brain arteriovenous malformation rupture with age clusterization. patients present with a GCS range between 14 - 15. Mostly, with full awareness of GCS 15 as much as $87.5 \%$ (Table 1). As can be seen in Fig. 1B, it was found that the highest percentage of rupture brain AVM by age was in ranges $10-19$ years and $20-29$ years, with $26.32 \%$ equally. The highest percentage of chief complaints was a seizure, which was about $43.75 \%$. The highest percentage of SpetzlerMartin grade in AVM rupture was grade I - II (52.94\%). Meanwhile, the highest percentage of Spetzler-Martin grade in intact AVM grade III and grade IV - V with $38.46 \%$ equally. In rupture AVM, the most common nidus size was $<3 \mathrm{~cm}$ (58.82\%) (Table 2). As can be seen in Fig. 2 , it was found that the highest percentage of Spetzler-Martin grading were grade I - II and grade IV - V with $40 \%$ equally. Embolization was the most common treatment modality in our study, which was about $43.34 \%$ (Table 1).

\section{DISCUSSION}

\section{Clinical consideration}

The profiles of brain AVM patients at the National Brain Center Hospital in 20152016 comprised a total of 32 patients (Table 1). In 2015, there were 13 people, and in 2016, there were 19 people. The male gender occupied the most significant number (Table 1). In 2007, Yamada et al. reported that the highest number of brain AVM patients was men. Still, the incidence of recurrent rupture of the brain AVM nidus with a hazard ratio of 2.93 increased significantly in women $(\mathrm{p}<0.05){ }^{2}$ In 1997 , Mast $e t$ al. reported in their research that most brain AVM patients were female, and with a multivariate regression test, it was found that men had a risk of brain AVM rupture with a risk ratio of 9.2 times which increased significantly $(\mathrm{P}<0.05){ }^{7}$

The most extensive age range found in brain AVM patients is $20-29$ years with $31.25 \%$; this range is classified as the productive age (Fig. 1A). This statement is in line with research conducted by Yamada et al. in 2007 and Hernesniemi in 2008, where a productive period had a greater risk of brain AVM rupture. It was found that all brain AVM patients present with a GCS range of $14-15$. Mostly with full awareness GCS 15 as much as $87.5 \%$ (Table 1). Based on the data obtained, in the table 


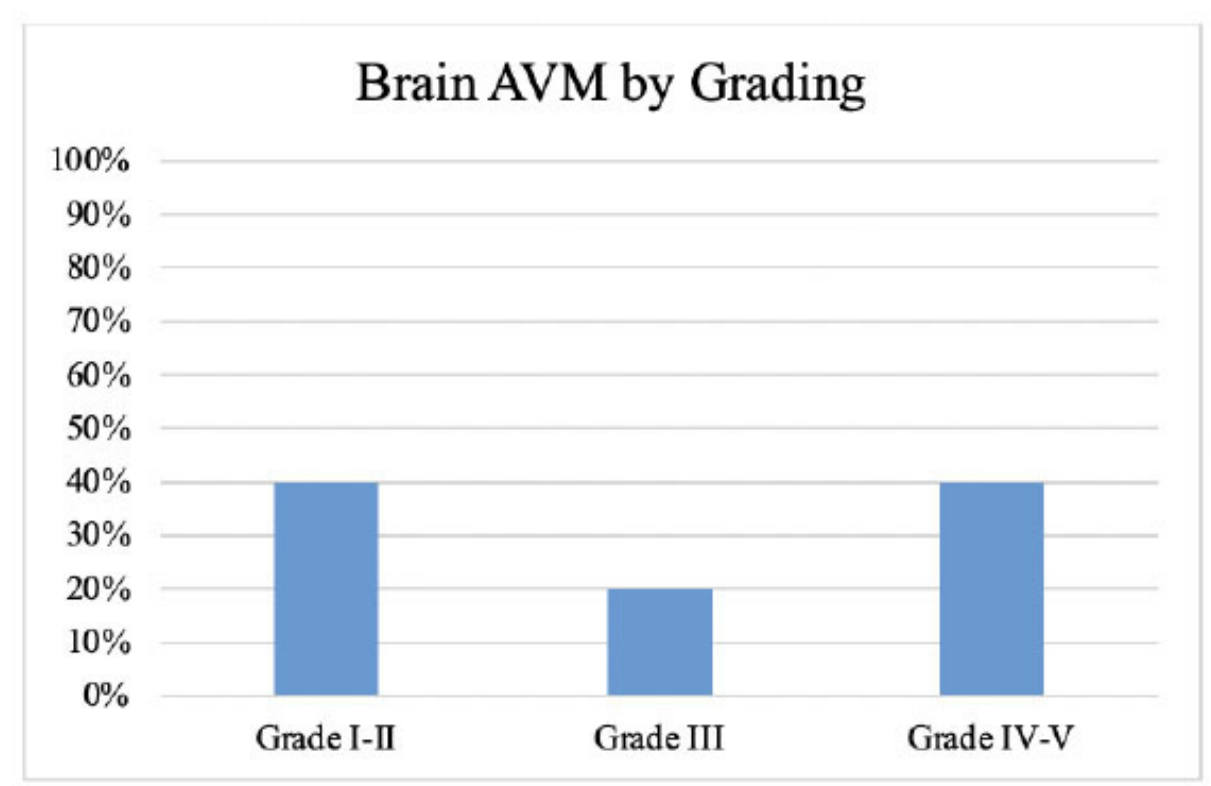

Figure 2. Prevalence of brain arteriovenous malformation with Spetzler-Martin grading clusterization.

Table 2. Prevalence of rupture and intact brain arteriovenous malformation.

\begin{tabular}{lcccc}
\hline \multirow{2}{*}{ Variable } & \multicolumn{2}{c}{ Ruptured } & \multicolumn{2}{c}{ Intact } \\
\cline { 2 - 5 } & $\mathbf{N}$ & $\%$ & $\mathbf{N}$ & $\%$ \\
\hline $\begin{array}{l}\text { Spetzler-Martin Grading } \\
\text { Grade I - II }\end{array}$ & $\underline{9}$ & 52.94 & 3 & 23.10 \\
Grade III & 1 & 5.88 & 5 & 38.46 \\
Grade IV - V & 7 & 38.89 & 5 & 38.46 \\
Nidus Size & & & & \\
$<3 \mathrm{~cm}$ & 10 & 58.82 & 4 & 30.77 \\
$3-6 \mathrm{~cm}$ & 4 & 23.53 & 7 & 53.85 \\
$>6 \mathrm{~cm}$ & 3 & 17.65 & 2 & 15.39 \\
\hline
\end{tabular}

of the occurrence of bleeding in brain AVM patients based on age, it was found that the highest percentage in ruptured nidus conditions were in the productive age in the range of $10-19$ years and $20-$ 29 years, with $26.32 \%$ equally (Fig. 1B)., ${ }^{2,8}$

The most clinical symptom complained in brain AVM patients was seizures with $43.75 \%$ (Table 1). Seizures could be caused by mass effects with cortical irritation or flow characteristics causing the steal phenomenon, neural damage, bleeding, or gliosis. ${ }^{9}$ Besides that, the headache was the second with $31.25 \%$, and hemiparesis was the third with $15.63 \%$, which could be caused by the mass effect to the motor cortex area or ischemia in the region. These complaints could be due to the mass effect of the brain AVM itself, brain AVM nidus rupture causing bleeding, hydrocephalus, or ischemia due to complications such as the steal phenomenon. ${ }^{9}$

\section{Radiological consideration}

The nidus condition of brain AVM patients with a ruptured state was $59.38 \%$. Usually, the complaint when they first came to the hospital was manifested as a hemorrhagic stroke (Table 1). In the table of brain AVM rupture based on Spetzler-Martin grading, it was found that the lower the grading, has the highest number of ruptured nidus (Table 2). In 2006, Stapf et al. reported that the size of the brain AVM nidus was a predictor of bleeding risk in untreated brain AVM patients. ${ }^{10}$ Langer et al. in 1998, and Kader et al. in 1994 had a similar opinion that a smaller nidus size is more likely to come to the hospital with a hemorrhagic stroke manifestation. ${ }^{11,12}$ Meanwhile, according to Mine et al., Stefani et al., Guidetti et al., and Laakso et al. stated in their cohort study that a large nidus size is a risk factor of AVM rupture. $^{1,13-15}$ In this study, the highest number of ruptures was found in patients with a nidus size $<3 \mathrm{~cm}(58.82 \%)$ (Table 2). This is probably due to the small size of the nidus; the manifestations have not yet resulted in complaints that are considered disturbing by the patient. When the nidus ruptures, it has significant implications as a result of the bleeding process itself. ${ }^{1}$ The small nidus tends to rupture due to the high pressure on the feeding artery. Meanwhile, large niduses have a higher risk of seizures due to direct pressure on the cortex. ${ }^{16}$

\section{Treatment consideration}

Based on Spetzler-Martin's grading, brain AVM patients were divided into three grades. In thisstudy, there were $40 \%$ of grade I - II, $20 \%$ of grade III, and $40 \%$ of grade IV - V (Fig. 2). Spetzler-Martin divided these grades based on the size of the nidus, the location of the nidus (eloquent), and the draining vein. This grading is related to the management that will be given to these patients. Grade I - II is managed with only one therapeutic modality, which is microsurgery or stereotactic radiosurgery (SRS). Grade III requires multimodality with adjuvant, which is endovascular embolization. It helps shrink the nidus, reduce the risk of bleeding and postoperative complications such as normal perfusion pressure breakthrough due to chronic low perfusion pressure in normal brain tissue surrounding the brain AVM nidus. ${ }^{5}$ Grade IV - V do not have any definitive (conservative) management. In patients with brain AVM SpetzlerMartin grade IV - V, microsurgery can be taken in the case of recurrent bleeding or bleeding accompanied by a neurological deficit. In addition, if there is a high steal phenomenon or the presence of an aneurysm on the feeding artery, partial embolization can be viewed to reduce the risk of recurrent bleeding. ${ }^{17}$ In our study, the most common treatment modality was embolization (43.34\%) (Table 1).

\section{CONCLUSION}

Brain arteriovenous malformation (AVM) is a rare vascular lesion with an incidence rate of 1 case in every 100,000 
population a year. However, the incidence of unruptured and asymptomatic brain AVM increase with the development of more advanced radiological support tools. The clinical manifestation of a brain AVM is mass effect that can be caused by bleeding due to brain AVM nidus rupture or mass effect caused by the brain AVM itself. Seizures and headaches are the most common clinical manifestation. Brain AVM predominantly occurs at a young age, and the management varies depending on the patient's Spetzler-Martin grading. In addition, the likelihood of rupture is influenced by the characteristics of the lesion, such as size, age, location of the nidus, and history of brain AVM nidus rupture.

\section{FUNDING}

No specific funding.

\section{CONFLICT OF INTEREST}

The authors have no conflict of interest.

\section{AUTHOR CONTRIBUTIONS}

The authors took part in the design of the study and contributed to data collection. $\mathrm{DD}, \mathrm{AA}$, and MARK did a literature review and drafted the manuscript. AA and MARK made critical revisions to the manuscript, and all authors agreed to accept equal responsibility for the accuracy of the contents of this article.

\section{REFERENCES}

1. Laakso A, Hernesniemi J. Arteriovenous malformations: Epidemiology and clinical presentation. Neurosurg Clin N Am. 2012; 23(1): 1 - 6. https://doi.org/10.1016/j.nec.2011.09.012.
2. Yamada S, Takagi Y, Nozaki K, Kikuta K, Hashimoto N. Risk factors for subsequent hemorrhage in patients with cerebral arteriovenous malformations. J Neurosurg. 2007; 107(5): 965 - 72. https://doi.org/10.3171/ INS-07/11/0965.

3. Spetzler RF, Martin NA. A proposed grading system for arteriovenous malformations. $J$ Neurosurg. 1986; 65(4): 476 - 83. https://doi. org/10.3171/jns.1986.65.4.0476.

4. Zacharia BE, Vaughan KA, Jacoby A, Hickman ZL, Bodmer D, Connolly Jr ES. Management of ruptured brain arteriovenous malformations. Curr Atheroscler Rep. 2012; 14(4): 335 - 42. https://doi.org/10.1007/s11883-012-0257-9.

5. Derdeyn CP, Zipfel GJ, Albuquerque FC, Cooke DL, Feldmann E, Sheehan JP, et al. Management of brain arteriovenous malformations: A scientific statement for healthcare professionals from the American Heart Association/ American Stroke Association. Stroke. 2017; 48(8): e200 - e224. https://doi.org/10.1161/ STR.0000000000000134.

6. Bajamal AH, Turchan A, Parenrengi MA, Wahyuhadi J, Subagio EA, Fauzi A Al, et al. AVM. In: Pedoman Nasional Pelayanan Kedokteran Ilmu Bedah Saraf. Edisi 1. Perhimpunan Spesialis Bedah Saraf Indonesia; 2016. p. $198-201$.

7. Mast H, Young WL, Koennecke HC, Sciacca RR, Osipov A, Pile-Spellman J, et al. Risk of spontaneous hemorrhage after diagnosis of cerebral arteriovenous malformation. Lancet. 1997; 350(9084): 1065 - 8. https://doi. org/10.1016/s0140-6736(97)05390-7.

8. Hernesniemi JA, Dashti R, Juvela S, Väärt K, Niemelä M, Laakso A. Natural history of brain arteriovenous malformations: A long-term follow-up study of risk of hemorrhage in 238 patients. Neurosurgery. 2008; 63(5): 823 - 9; discussion 829 - 31. https://doi.org/10.1227/01. NEU.0000330401.82582.5E.

9. Flemming KD, Brown RD. Epidemiology and natural history of intracranial vascular malformation. In: Winn HR (Ed.) Youman \& Winn Neurological Surgery. 7th edition. Philadelphia: Elsevier; 2017. p. 3446 - 50.

10. Stapf C, Mast H, Sciacca RR, Choi JH, Khaw AV, Connolly ES, et al. Predictors of hemorrhage in patients with untreated brain arteriovenous malformation. Neurology. 2006; 66(9): 1350 - 5. https://doi.org/10.1212/01. wnl.0000210524.68507.87.

11. Langer DJ, Lasner TM, Hurst RW, Flamm ES, Zager EL, King Jr JT. Hypertension, small size, and deep venous drainage are associated with risk of hemorrhagic presentation of cerebral arteriovenous malformations. Neurosurgery. 199 8; 42(3): 481 - 6; discussion 487 - 9. https:// doi.org/10.1097/00006123-199803000-00008.

12. Kader A, Young WL, Pile-Spellman J, Mast $\mathrm{H}$, Sciacca RR, Mohr JP, et al. The influence of hemodynamic and anatomic factors on hemorrhage from cerebral arteriovenous malformations. Neurosurgery. 1994; 34(5): 801 - 7; discussion 807 - 8. https://doi. org/10.1227/00006123-199405000-00003.

13. Mine S, Hirai S, Ono J, Yamaura A. Risk factors for poor outcome of untreated arteriovenous malformation. J Clin Neurosci. 2000; 7(6): 5036. https://doi.org/10.1054/jocn.2000.0743.

14. Guidetti B, Delitala A. Intracranial arteriovenous malformations. Conservative and surgical treatment. J Neurosurg. 1980; 53(2): 149 - 52. https://doi.org/10.3171/jns.1980.53.2.0149.

15. Stefani MA, Porter PJ, TerBrugge KG, Montanera W, Willinsky RA, Wallace MC. Large and deep brain arteriovenous malformations are associated with risk of future hemorrhage. Stroke. 2002; 33(5): 1220 - 4. https://doi. org/10.1161/01/str.0000013738.53113.33.

16. Greenberg MS. Vascular malformations. In: Greenberg MS (Ed) Handbook of Neurosurgery. 9th edition. New York: Thieme Medical Publishers; 2019. pp. 1098 - 104.

17. Zanaty $M$, Chalouhi N, Tjoumakaris S, Rosenwasser R, Jabbour P. Intracranial arteriovenous malformations and dural arteriovenous fistulas. In: Kumar M, Kofke W, Levine J, Schuster J (Eds.) Neurocritical Care Management of the Neurosurgical Patient. 1st edition. Philadelphia: Elsevier; 2018. pp. 105 13.

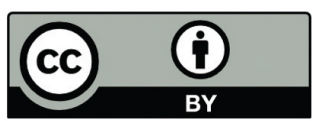

This work is licensed under a Creative Commons Attribution 